\title{
SHEAR RESISTANCE OF NOVEL PERFORATED SHAPED STEEL-ENGINEERED CEMENTITIOUS COMPOSITE (ECC) CONNECTORS
}

\author{
Li-min Tian ${ }^{1,2}$, Ting Liu ${ }^{1}$, Tian-ji Li ${ }^{3, *}$, and Hai-liang Lin $^{1}$ \\ ${ }^{1}$ Shaanxi Key Lab of Structure and Earthquake Resistance, School of Civil Engineering, Xi'an University of Architecture and Technology, Xi'an, China \\ ${ }^{2}$ State Key Laboratory of Subtropical Building Science, South China University of Technology, Guangzhou, China \\ ${ }^{3}$ Shanghai Construction No.5 (Group) Co., Ltd., Shanghai, China \\ *(Corresponding author: E-mail: tianji.li@connect.polyu.hk)
}

\section{A B S T RA C T}

A novel perforated shaped steel-engineered cementitious composite connector (PSSEC) is proposed in this paper based on the advantages of perforated plate connectors and engineered cementitious composite (ECC) materials. Eight short columns were designed to thoroughly investigate the mechanical mechanism, bearing capacity, and failure mode. Additionally, an equation for calculating the bearing capacity of PSSECs is presented. The results demonstrate that all eight short columns show splitting failure of the ECC or concrete. Moreover, it is determined that the cracks associated with the ECC specimens are smaller than those of the concrete specimen. Due to the effect of the perforated steel reinforcements, the PSSECs exhibit the characteristics of ductile failure. The load-slip curves of the PSSEC short columns can be divided into five stages: the no-slip, slip, yield, falling, and load residual stages. The load-slip curves of the perforated shaped steel-ECC connector without perforated steel reinforcement (PSSECW), perforated shaped steel-concrete connector (PSSCC), and shaped steel reinforced ECC (SSRE) possess no yield stage because of the absence of the perforated steel reinforcement or ECC. Except for the ultra-high-strength ECC90, the theoretical results obtained for the bearing capacity equation of the PSSECs are generally consistent with the test results.
A R T I C LE H IS T O RY

$\begin{array}{ll}\text { Received: } & \text { 26 July } 2019 \\ \text { Revised: } & \text { 12 September } 2019 \\ \text { Accepted: } & \text { 19 September } 2019\end{array}$

\section{K E Y W O R D S}

Perforated shaped steel;

ECC;

Short column;

Push-out test;

Shear performance

\section{Introduction}

ECC possesses excellent characteristics, including low weight, superior ductility, and good seismic performance [1-2]. The energy dissipation capacity and the overall seismic performance of structures can be enhanced using ECC materials [3-4]. It is extremely helpful to improve the collapse resistance of structures [5-6]. Zhou et al. [7] performed uniaxial compression tests on ECC with different mix proportions and compressive strengths. Xu and Cai [8] studied the compressive performances of ultra-high toughness cementitious composites and proposed the constitutive models. In addition, the basic mechanical properties of ultra-high ductility cementitious composites were obtained [9].

In steel-concrete composite members, the effectiveness of the bonding between steel and concrete is vital for these components to work together [10-12]. Due to the low bonding strength between shaped steel and concrete (the bond strength between shaped steel and concrete is approximately $1 / 3$ that of concrete and steel reinforcements [13]), the shear connectors (e.g., stud, steel channel, bend reinforcement, perforated plate connector, etc.) are frequently used to improve the bonding behavior. Ding et al. [14] proposed a slip-released connector and tested the slipping behaviors of the connectors.

Perforated steel plate connectors have broad application prospects because of their simple manufacturing process and good mechanical properties [15-17]. Numerous scholars have investigated perforated steel plate connectors to date, and several theories and equations have been proposed. He et al. [18] studied the force transfer mechanism of the perforated plate connector, and the influence of the position of perforated steel reinforcements on its ductility. Moreover, an equation for the perforated plate connector was derived. Cândido-Martins et al. [19] analyzed the influences of the number of hole rows and the amount of steel reinforcements on the mechanical performances of the perforated plate connector. Hosseinpour et al. [20] compared the bearing capacity as well as the failure mode of the rectangular hole perforated plate connector and those of the circular hole perforated plate connector. Zhao et al. [21] and Su et al. [22] analyzed the hole diameter of the perforated plate connector, the diameter of the perforated steel reinforcement, and the stirrup ratio. Costa-Neves et al. [23] investigated a T-type perforated plate shear connector and they performed a theoretical model. Gu et al. [24] researched a comb-type perforated plate connector and compared it with the traditional perforated plate connector to verify its superiority. Zuo et al. [25] considered a bridge panel with the perforated plate connector as an object; they analyzed the failure mode and ultimate bearing capacity of the bridge panel by changing the hole spacing and the diameter of the perforated steel reinforcements. Zhang et al. [26] studied the deformation of the perforated steel reinforcement under long-term load, as well as the relative slip between the perforated plate connector and concrete. Di et al. [27] derived a bearing capacity equation for the perforated plate connector. However, due to the use of different analytical methods, the aforementioned equations are substantially different. In the literature [28], several equations have been compared; then, it has been determined that the maximum result obtained using these equations can be greater than 4 times the minimum result.

Based on the advantages of perforated plate connectors and ECC materials, a novel PSSEC is proposed in this paper. The novel connector is composed of $\mathrm{H}$-shaped steel that is reinforced using perforated steel reinforcements, and wrapped with ECC material, as shown in Fig. 1. The integrity of a shaped steel reinforced ECC can be improved by the perforated steel reinforcements. Eight short columns were designed to thoroughly investigate the mechanical mechanism, bearing capacity, and failure mode. Additionally, a calculation method for the PSSECs is presented.

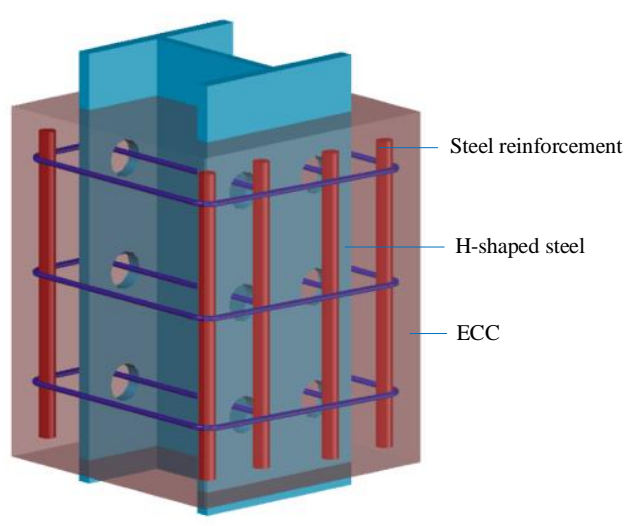

Fig. 1 The push-out test model

\section{Experimental details}

\subsection{Test materials}

The ECC was composed of common Portland cement, mineral admixture, silica sand, ultra-high-molecular-weight polyethylene fiber, silica fume, water-reducing admixture, and water preparation, as displayed in Table 1. The concrete was adopted commercial concrete with a design strength of $30 \mathrm{MPa}$. The ECC and concrete were tested for its compressive strength in the form of three cubes $(100 \mathrm{~mm} \times 100 \mathrm{~mm} \times 100 \mathrm{~mm})$, respectively. The mean values of the compressive strength are depicted in Table 2. 
All H-shaped steels were constructed from Grade Q235 steel and were $\mathrm{H} 200 \times 200 \times 12 \times 16 \mathrm{~mm}$. Some penetrating holes with diameter of $40 \mathrm{~mm}$ were opened on the flange of shaped steel. Both the stirrups and longitudinal reinforcements used were HRB335 grade, with diameters of $8 \mathrm{~mm}$ and $12 \mathrm{~mm}$, respectively. Table 3 lists the measured material properties of the steel plates and steel reinforcement.

Table 1

Mixture properties of the ECC $\left(\mathrm{kg} / \mathrm{m}^{3}\right)$

\begin{tabular}{cccccccc}
\hline Strength grade & Cement & Silica sand & Mineral admixture & Water & Silica fume & Water-reducing admixture \\
\hline ECC45 & 220.8 & 396.8 & 1104.4 & 380.0 & 6.6 & 8.0 \\
ECC60 & 330.6 & 396.8 & 991.8 & 396.7 & 16.5 & 15.0 \\
ECC90 & 528.9 & 396.8 & 793.4 & 327.0 & 158.7 & 15.0 & 10.0 \\
\hline
\end{tabular}

Table 2

Measured material properties of the ECC and concrete $\left(\mathrm{N} / \mathrm{mm}^{2}\right)$

\begin{tabular}{clccc}
\hline Strength grade & \multicolumn{3}{c}{ Measured strength (three trials) $f_{\mathrm{c}}$} & Mean strength $f_{\mathrm{c}}$ \\
\hline C30 & 27.21 & 29.34 & 28.53 & 28.36 \\
ECC45 & 44.04 & 47.15 & 46.05 & 45.75 \\
ECC60 & 55.95 & 58.16 & 59.28 & 57.79 \\
ECC90 & 92.25 & 94.37 & 99.48 & 95.37 \\
\hline
\end{tabular}

Table 3

Measured material properties of the steel plates and steel reinforcement

\begin{tabular}{ccccc}
\hline $\begin{array}{c}\text { Type of } \\
\text { steel }\end{array}$ & $\begin{array}{c}\text { Young's modulus } \\
\left(\mathrm{N} / \mathrm{mm}^{2}\right)\end{array}$ & $\begin{array}{c}\text { Yield strength } \\
\left(\mathrm{N} / \mathrm{mm}^{2}\right)\end{array}$ & $\begin{array}{c}\text { Ultimate strength } \\
\left(\mathrm{N} / \mathrm{mm}^{2}\right)\end{array}$ & $\begin{array}{c}\text { Elongation } \\
\text { rate }(\%)\end{array}$ \\
\hline Web of & & & & \\
H-shaped & $2.11 \times 10^{5}$ & 336.67 & 470.00 & 28.93 \\
steel & & & & 30.58 \\
Flange of & & & 441.67 & \\
H-shaped & $2.09 \times 10^{5}$ & 278.33 & & \\
steel & & & & \\
Steel & $2.06 \times 10^{5}$ & 324.08 & & \\
reinforce & & & & \\
\hline
\end{tabular}

\subsection{Specimen design}

The bonding stress between shaped steel and ECC has a non-uniform distribution. The outer flange of shaped steel bears most of the load by studying on interfacial behavior of shaped steel reinforced ECC. Considering the strength of ECC, we investigated variations of the structural characteristics of the flange of shaped steel, such as the perforations, the steel reinforcements in the holes, and the spacing of the holes, for a total of eight specimens. The specimens included five PSSEC short columns, one PSSECW short column, one PSSCC short column, and one SSRE short column. Compared with the PSSECs, PSSECW possessed no perforated steel reinforcement in the holes of shaped steel. PSSCC was composed of the shaped steel that was reinforced using perforated steel reinforcements and wrapped with concrete material. SSRE was only wrapped with ECC material outside of the non-perforated shaped steel. The specific dimensions of these specimens are manifested in Fig. 2 ; and the specific parameters of each specimen are shown in Table 4.
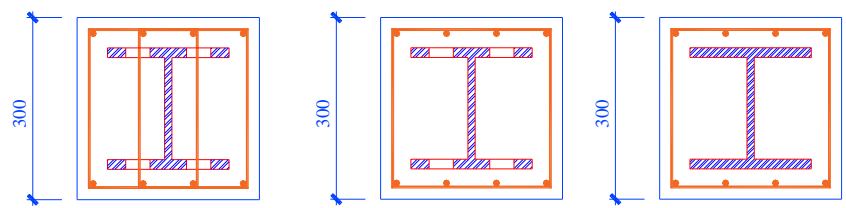


$$
\gtrless^{50} k^{94} \ln ^{2} 94 k^{50} k
$$

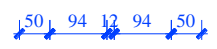

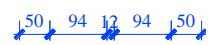

(a) PSSEC-2 and PSSCC

(b) PSSECW

(c) SSRE

Fig. 2 Specific dimensions of the specimens (all dimensions shown are in $\mathrm{mm}$ )

Table 4

Design parameters of the specimens

\begin{tabular}{ccccc}
\hline Specimen & Material & $\begin{array}{c}\text { Strength } \\
\left(\mathrm{N} / \mathrm{mm}^{2}\right)\end{array}$ & $\begin{array}{c}\text { Hole spacing } \\
(\mathrm{mm})\end{array}$ & $\begin{array}{c}\text { Perforated steel } \\
\text { reinforcement }\end{array}$ \\
\hline SSRE & ECC & 45 & $/$ & $/$ \\
PSSCC & Concrete & 30 & 120 & $\sqrt{ }$ \\
PSSECW & ECC & 60 & 120 & $/$ \\
PSSEC-1 & ECC & 45 & 120 & $\sqrt{ }$ \\
PSSEC-2 & ECC & 60 & 120 & $\sqrt{ }$ \\
PSSEC-3 & ECC & 60 & 90 & $\sqrt{ }$ \\
PSSEC-4 & ECC & 60 & 180 & $\sqrt{ }$ \\
PSSEC-5 & ECC & 90 & 120 & \\
\hline
\end{tabular}

\subsection{Loading and measuring method}

The test was performed on a YAS-5000 kN electro-hydraulic servo pressure testing machine, as displayed in Fig. 3. The two ends of the shaped steel were the loading end and free end. The top of the shaped steel was fixed with the testing machine. The bottom of ECC/concrete was fixed with the loading platform via the special support, and the shaped steel was free. The load was performed with displacement control at a rate of $0.003 \mathrm{~mm} / \mathrm{s}$. When the displacement achieved approximately $30-40 \mathrm{~mm}$ or the external ECC/concrete cracked obviously, the load was terminated. The real-time load at the loading end was obtained using a pressure transducer. The displacements of the loading end and free end were measured with four linear variable differential transformers (LVDTs) that were set up at the steel plate and ECC, as depicted in Fig. 3. In addition, the strains and displacements on the surface of ECC/concrete were acquired in real-time using a Visual Image Correlation-3D (VIC-3D) non-contact full-field strain measurement system. The system can provide the data of full-field shape, displacement, and strain in three-dimensional space [28], as shown in Fig. 4. 


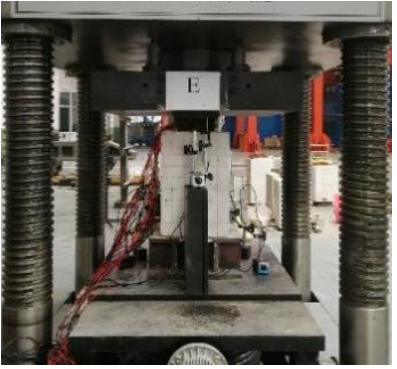

(a) Specimen fitted into test rig (b) Test device

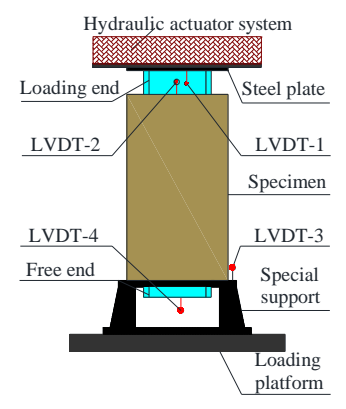

Fig. 3 The push-out test set-up

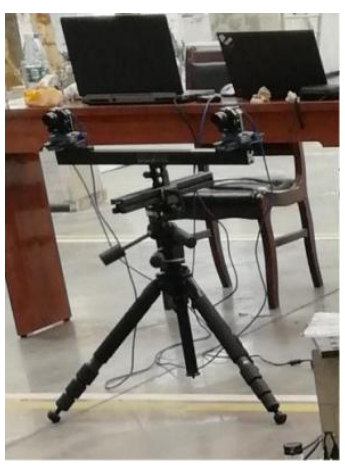

(a) Measurement device



(b) Specimen
Fig. 4 The non-contact full-field measurement system

\section{Test results and analysis}

\subsection{PSSECs and PSSECW short columns}

\subsubsection{Failure mode} and PSSECW. PSSEC-2 can be used as an example (Fig. 5). When the load increased to a certain level, cracks began to appear on the surface for the first time. The cracks were small and located at the loading end on the surface of the specimen (Fig. 5a). With the increase of the load, the number of cracks increased. The cracks gradually widened and extended from the loading end to the free end (Fig. 5b). As cracks developed, the specimen reached the ultimate load. Finally, the interface between the shaped steel and ECC exhibited push-out failure (Fig. 5c).

The test results demonstrated that the surface cracks of the ECC in the outer flange of shaped steel direction were distributed in the position of or

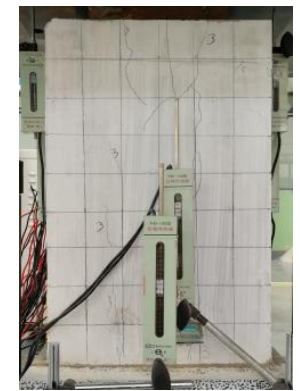

(a) Initial crack

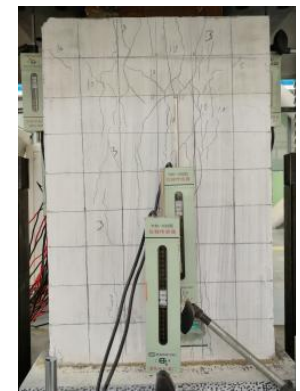

(b) Mid-stage crack

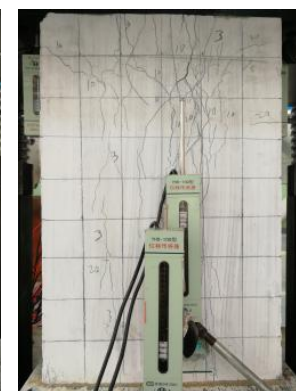

(c) End-stage crack
Fig. 5 Failure phenomena of PSSEC-2
Splitting failure of the ECC material occurred in all specimens PSSECs between two rows of the holes.

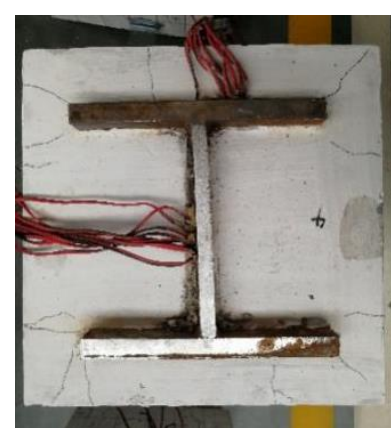

(a) The first type of crack

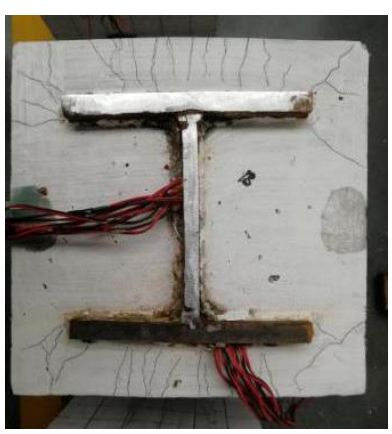

(b) The second type of crack
Fig. 6 Typical fracture modes

\subsubsection{Z-direction displacement and strain}

Considering the PSSEC-2, PSSEC-5, and PSSECW as examples, the strain field and displacement field on the surface of the ECC are illustrated in Fig. 7. The results indicate the following.

(1) The principal strain on the surface of ECC is distributed in the position of two rows of holes or between two rows of holes. The principal strain of ECC decreases gradually from the loading end to the free end which indicates that the shear force is transferred from the loading end to the free end.

(2) The principal strain field is approximately identical to the $X$-direction strain field, while the $Y$-direction strain field is relatively small, indicating that the principal strain is generally controlled by the $X$-direction strain. This is because the external ECC tends to split along the $Y$-direction during the loading process.

(3) The principal strain of the PSSEC-5 is smaller than that of PSSEC-2 and PSSECW, which indicates that the ductility of the latter materials is excellent, while that of the ultra-high-strength (ECC90) material is relatively unsatisfactory.

(4) The Z-displacement on the surface of ECC is generally distributed in the corresponding region of the flange of shaped steel. The maximum displacement is located in the middle and upper portions of this region, and gradually decreases to the outer ring. The $Z$-displacement indicates that the ECC on one side of the flange of shaped steel causes a significant restraint effect on the internal perforated shaped steel shear connectors.

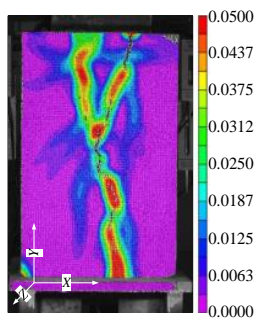

(a) Principal strain field of PSSEC-2



(c) $X$-strain field of PSSEC-2

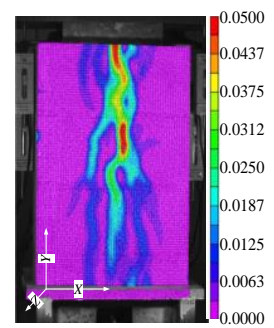

(b) Principal strain field of PSSECW

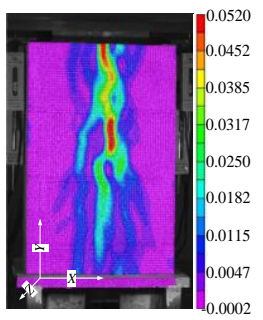

(d) $X$-strain field of PSSECW

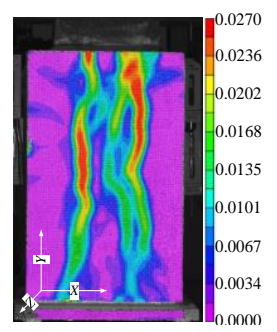

(c) Principal strain field of PSSEC-5

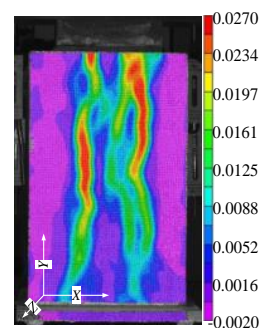

(e) $X$-strain field of PSSEC-5
The cracks of the loading end in the specimens PSSECs and PSSECW can be summarized into the following two types. The first type of cracks only appears near the limb tips of the flange of shaped steel. The second type possesses more vertical cracks in the ECC of the outer flange of shaped steel; this type of cracks occurs because the perforated steel reinforcements and ECC resist the downward load together. The first type of cracks appeared in the PSSECW because this specimen did not have the perforated steel reinforcement (Fig. 6a). The second type of cracks appeared in the PSSECs (Fig. 6b). 

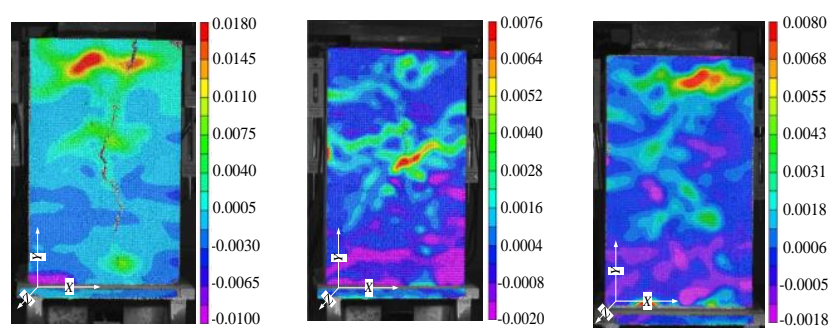

(f) $Y$-strain field of PSSEC-2

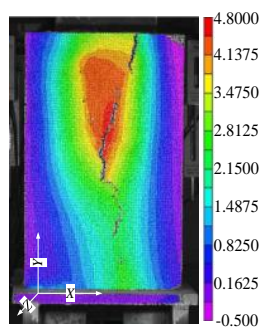

(i) Z-displacement field of PSSEC-2 (g) $Y$-strain field of PSSECW

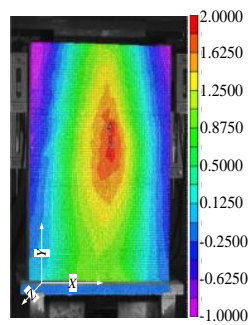

(j) Z-displacement field of PSSECW

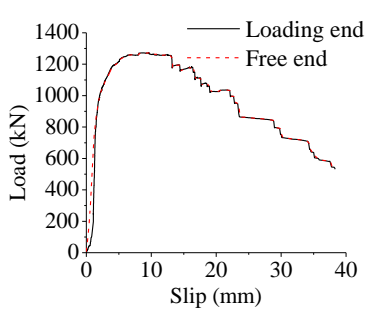

(a) PSSEC-1

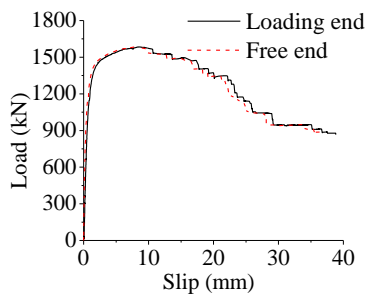

(c) PSSEC-3

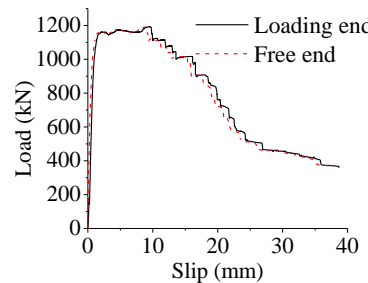

(b) PSSEC-2

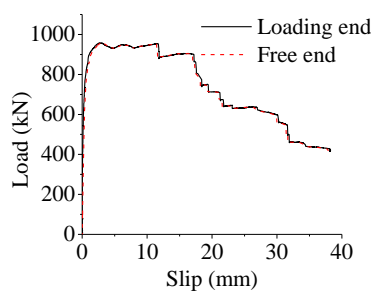

(d) PSSEC-4

Fig. 7 Strain and displacement fields

The points with large displacement in the $Z$-displacement field nephogram are selected. The $Z$-displacement-slip curves and the principal strain-slip curves are revealed in Fig. 8. From the results, at the initial stage of loading, the $Z$-displacement on the surface of ECC increases for the majority of the specimens, and remains constant when the displacement increases to a certain threshold. Additionally, the non-ultra-high-strength ECC displays excellent ductility. The perforated steel reinforcements cause the PSSEC-2 to exhibit ductile failure.
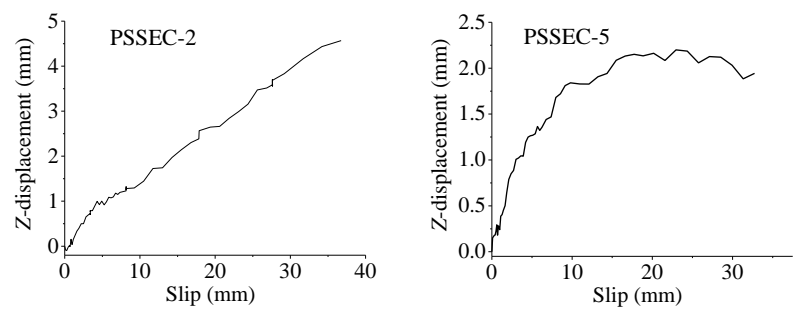

(a) Z-displacement-slip curves
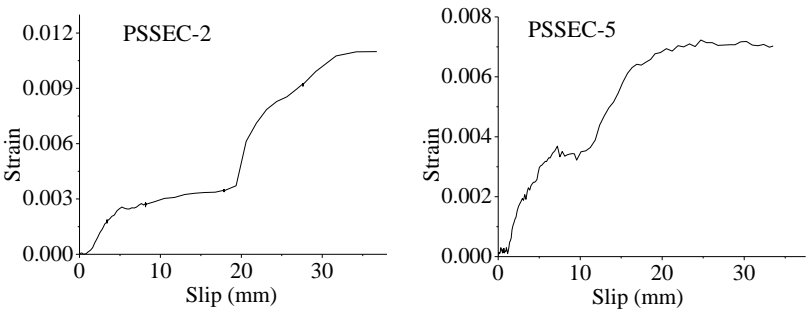

(b) Principal strain-slip curves

Fig. 8 Z-displacement-slip and principal strain-slip curves

\subsubsection{Load-slip curves}

(1) PSSECs

Fig. 9 displays the load-slip curves of the loading end and free end in the PSSECs. From the observation of Fig. 9, the trend of the load-slip curves at the loading end is approximately identical to that at the free end. Overall, there is hysteresis in the relative slip of the free end. The load-slip curves of the PSSECs can be simplified to the models shown in Fig. 10. Based on these results, the load-slip curves can be divided into the following five stages:

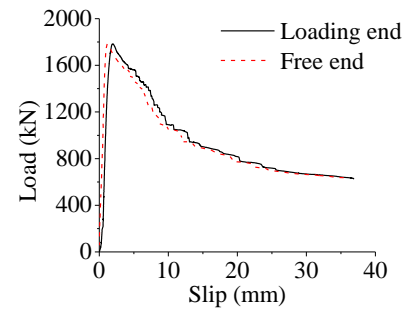

(e) PSSEC-5

Fig. 9 Load-slip curves of PSSECs

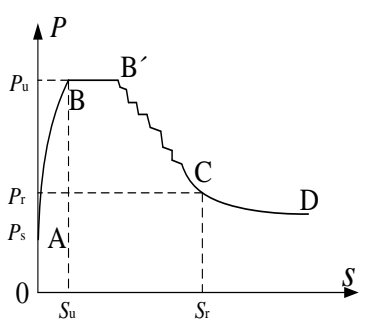

(a) Non-ultra-high-strength ECC

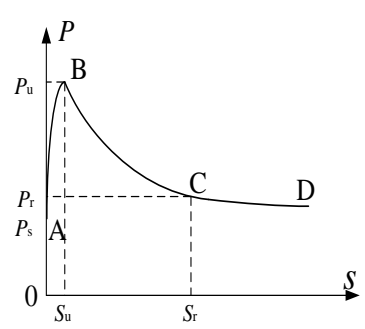

(b) Ultra-high-strength ECC
Fig. 10 Typical load-slip curves of PSSECs

1) No-slip stage (OA segment). During the initial stage of loading, the loading end and the free end of each specimen do not possess a significant relative slip. The chemical adhesion between the shaped steel and the ECC plays a major role in bonding. Moreover, the perforated shaped steel shear connector has not yet functioned at this stage.

2) Slip stage (AB segment). When the load achieves the initial slip load $P_{\mathrm{s}}$ the loading end appears to slip firstly while the slippage of free end is not apparent. At this time, the bonding force gradually fails from the loading end to the free end. Additionally, the longitudinal load is transferred by the frictional force and the shear resistance of the perforated shaped steel shear connector. When the load exceeds $50 \%$ of the ultimate load $P_{\mathrm{u}}$, the slippage of the loading end develops quickly. Moreover, the slippage begins to occur at the free end.

3) Yield stage (BB' segment for Fig.10a). Except for the ultra-high-strength ECC specimen (PSSEC-5, bad ductility of ultra-high-strength ECC90), the slippage of the loading end and free end increases rapidly after the load reaches the peak and the load remains almost constant.

4) Falling stage ( $\mathrm{B}^{\prime} \mathrm{C}$ segment for Fig.10a and $\mathrm{BC}$ segment for Fig.10b). After the load reaches the peak, the cracks of ECC are fully developed. Additionally, the load-slip curves are in a descending state until the load reaches the residual load $P_{\mathrm{r}}$. For the non-ultra-high-strength ECC specimens, the load-slip curve is in a descending state with step-shaped behavior.

5) Load residual stage (CD segment). With the increase of the slip amount, the load is stabilized. 


\section{(2) PSSECW}

The load-slip curves of the PSSECW are illustrated in Fig. 11. It is evident that these curves can be divided into four stages, namely, the no-slip, slip, falling, and load residual stages. Due to the absence of the perforated steel reinforcement, the ECC in the holes experiences brittle failure under the action of the shear force. Therefore, the curves possess no yield stage.

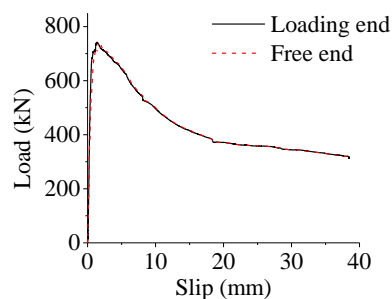

Fig. 11 Load-slip curves of PSSECW

\subsubsection{Summary of test results}

Table 5 shows the ultimate loads, slippages of the loading end and free end corresponding to the ultimate loads.

Table 5

Test results of PSSECs and PSSECW

\begin{tabular}{cccc}
\hline Specimen & Ultimate load $(\mathrm{kN})$ & Loading-end slip $(\mathrm{mm})$ & Free-end slip (mm) \\
\hline PSSECW & 741.82 & 1.37 & 1.65 \\
PSSEC-1 & 1272.23 & 8.68 & 8.72 \\
PSSEC-2 & 1193.21 & 9.46 & 8.77 \\
PSSEC-3 & 1584.46 & 8.47 & 7.74 \\
PSSEC-4 & 957.42 & 2.75 & 2.97 \\
PSSEC-5 & 1783.84 & 1.91 & 1.14 \\
\hline
\end{tabular}

With the increase of the number of hole rows, the ultimate bearing capacity increases approximately linearly. With the increase of the strength of ECC, the ultimate bearing capacity tends to increase. The mean ultimate bearing capacity of the specimens with perforated steel reinforcements is approximately $60 \%$ higher than that of the specimen without the perforated steel reinforcement.

\subsection{PSSCC and SSRE short columns}

\subsubsection{Failure mode}

The failure mode of the PSSCC and SSRE was splitting failure of the ECC or concrete. It is noteworthy that the surface cracks of PSSCC were wider than those of the ECC specimens because of the bad ductility of concrete. In addition, the spalling and transverse cracks of the concrete appeared (Fig. 12).


Fig. 12 The failure mode of PSSCC

After the experiment was finished, the specimen PSSCC was smashed to directly observe the failure of the perforated steel reinforcements and concrete in the holes. The failure states are described in Fig. 13. It is evident that the fractures of concrete in the holes were non-uniform. Moreover, a portion of concrete in the holes was crushed. The steel reinforcements in the holes were cut off and no longer possessed shear resistance. The steel reinforcements in the holes were shear failure along the $45^{\circ}$ angle, accompanied by slight necking, which indicated that the steel reinforcements in the holes were subjected to tension. Moreover, the steel reinforcements in the holes were bent.

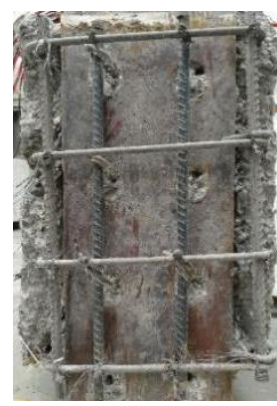

(a) Overview

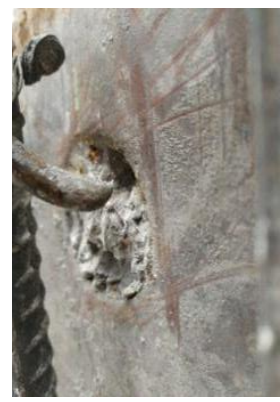

(b) Details

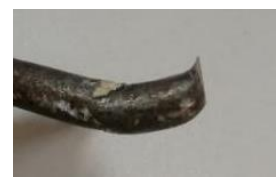

Fig. 13 Failure states of the perforated steel reinforcements and concrete in the holes

\subsubsection{Load-slip curves}

The load-slip curves of the PSSCC and SSRE can be divided into four stages: the no-slip, slip, falling, and load residual stages, as manifested in Fig. 14. Compared with the load-slip curves of the PSSECs, the PSSCC and SSRE do not exhibit the yield stage. The PSSCC exhibits a slow decline with step-shaped behavior after it achieves the ultimate load, indicating that the ductility of this specimen is worse than that of the PSSECs.

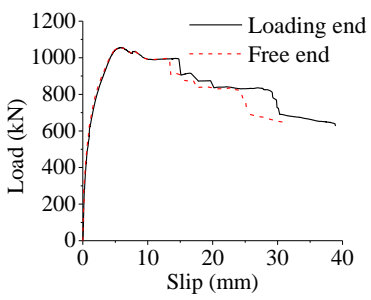

(a) PSSCC

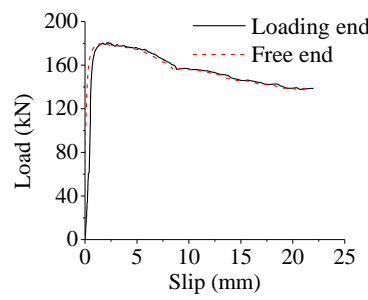

(b) SSRE
Fig. 14 Load-slip curves of PSSCC and SSRE

Table 6 shows the ultimate loads of the PSSCC and SSRE in addition to the slippages of the loading end and free end corresponding to the ultimate loads. It is evident that the slippage of PSSCC under the ultimate load is significantly less than those of the PSSECs. Moreover, the ultimate bearing capacity of the perforated shaped steel-ECC45 is approximately 7 times that of SSRE when the ECC is of identical strength.

Table 6

Test results of PSSCC and SSRE

$\begin{array}{lll}\text { Specimen } & \text { Ultimate load }(\mathrm{kN}) \quad \text { Loading-end slip (mm) } & \text { Free-end slip (mm) }\end{array}$

\begin{tabular}{cccc}
\hline SSRE & 180.21 & 1.74 & 1.42 \\
PSSCC & 1055.64 & 5.78 & 5.75 \\
\hline
\end{tabular}

Based on these test results and analyses, it is evident that the failure mode of the PSSECW and PSSCC is brittle failure, while that of the PSSECs is ductile failure (except for the ultra-high-strength ECC90). Because of the perforated steel reinforcements, the bearing capacity of the PSSECs is improved and the brittle failure is avoided.

\section{Analysis of the bearing capacity of PSSECs}

Because the ultimate bearing capacity of the PSSECs increased linearly with the increase of the number of hole rows, the bearing capacity of multiple holes can be analyzed and calculated using theories of a single hole.

\subsection{Analysis of bearing capacity of a single hole}

The shear bearing capacity of a perforated plate connector can be divided into three parts [29]: the compressive bearing capacity of ECC/concrete at the end of a perforated steel plate, the shear bearing capacity of ECC/concrete in the hole, and the shear bearing capacity of a perforated steel reinforcement.

Fig. 15 reveals the stress of ECC in the perforated shaped steel connector. The ECC in the hole is constrained by ECC on both sides of the flange of 
shaped steel. Additionally, it is subjected to the circumferential compression of the hole wall. The ECC in the hole can be regarded as existing in a three-dimensional compressive state. The compressive bearing capacity of ECC at the end of the perforated steel plate does not exist in the PSSECs. Therefore, its shear bearing capacity comprises two parts: the shear capacity of ECC in the hole and the shear capacity of a perforated steel reinforcement.
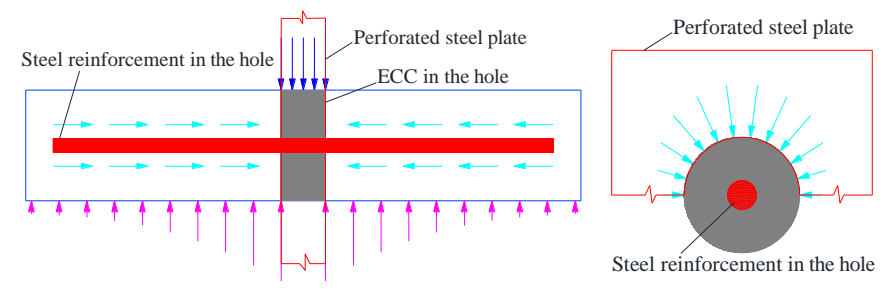

Fig. 15 The stress analysis of ECC in the hole

Because the perforated steel reinforcement is simultaneously subjected to both shear and tensile forces, its actual shear bearing capacity is larger than the pure shear bearing capacity. Therefore, it is necessary to multiply the shear bearing capacity by a magnification factor when calculating the shear strength of the steel reinforcement.

\subsection{Equations of bearing capacity of a single hole}

According to the literature [30], the shear bearing capacity of ECC in the hole under two shear planes $\left(P_{\mathrm{E}}\right)$ can be calculated as follows (it is assumed that the magnification factor is five):

$$
P_{\mathrm{E}}=3.9 A_{\mathrm{E}} f_{\mathrm{cu}}^{0.57}
$$

where $A_{\mathrm{E}}$ is the area of ECC in the hole under a single shear plane, $A_{\mathrm{E}}=$ $\pi\left(d_{1}^{2}-d_{2}^{2}\right) / 4 ; d_{1}$ is the diameter of the hole; $d_{2}$ is the diameter of the perforated steel reinforcement; $f_{\mathrm{cu}}$ is the standard compressive strength of the ECC.

According to the test results of the PSSEC-2 and PSSECW, the bearing capacity can be increased by $28.2 \mathrm{kN}$ for each steel reinforcement in the hole. On the other hand, the pure shear bearing capacity of steel reinforcement in the hole is $18.8 \mathrm{kN}$. Therefore, the shear magnification factor under a single shear plane is approximately 1.5 . The ultimate shear bearing capacity of a single perforated steel reinforcement under two shear planes $\left(P_{\mathrm{s}}\right)$ is:

$P_{\mathrm{s}}=3 A_{\mathrm{s}} \tau_{\mathrm{u}}$

where $A_{\mathrm{u}}$ is the cross-sectional area of a single perforated steel reinforcement and $\tau_{\mathrm{u}}$ is the shear strength of the steel reinforcement.

It can be concluded that the bearing capacity of a single hole for a perforated shaped steel-ECC connector $(P)$ is:

$P=3.9 A_{\mathrm{E}} f_{\mathrm{cu}}^{0.57}+3 A_{\mathrm{s}} \tau_{\mathrm{u}}$

To verify the correctness of the proposed equations, the experimental parameters are substituted into the Eq. (3) and the calculation results are compared in Table 7.

Table 7

Comparisons of the ultimate bearing capacities

\begin{tabular}{cccc}
\hline Specimen & Test results (kN) & Theoretical results (kN) & Difference (\%) \\
\hline PSSECW & 741.82 & 791.46 & 6.69 \\
PSSEC-1 & 1272.23 & 1116.53 & 12.23 \\
PSSEC-2 & 1193.21 & 1211.26 & 1.51 \\
PSSEC-3 & 1584.46 & 1514.07 & 4.44 \\
PSSEC-4 & 957.42 & 908.44 & 5.12 \\
PSSEC-5 & 1783.84 & 1462.36 & 18.02 \\
\hline
\end{tabular}

In the above comparisons, it is clear that, except for the perforated shaped steel-ECC90, the theoretical results are in good agreement with the experimental results, which indicates that the Eq. (3) is reliable for non-ultra-high-strength ECC. The ultimate bearing capacity of the perforated shaped steel-ECC30 is $957.85 \mathrm{kN}$ by using Eq. (3), which is only $9.26 \%$ (within 10\%) different from the ultimate load of the PSSCC in the experiment.

\section{Conclusions}

Eight short columns were designed to thoroughly investigate the mechanical mechanism, bearing capacity, and failure mode; additionally, a calculation method for PSSECs is proposed. The following conclusions are drawn.

(1) The failure mode of the PSSECs, PSSECW, PSSCC, and SSRE short columns is either ECC or concrete splitting failure. The cracks in the PSSECs, PSSECW, and SSRE are microcracks and multi-cracks. The cracks of the PSSCC are wider than those of the ECC specimens.

(2) Due to the effect of the perforated steel reinforcements, the PSSECs exhibit the characteristics of ductile failure.

(3) The load-slip curves of the PSSEC short columns can be divided into five stages: the no-slip, slip, yield, falling, and load residual stages. The load-slip curves of the PSSECW, PSSCC, and SSRE short columns possess no yield stage due to the absence of the perforated steel reinforcement or ECC.

(4) An equation for calculating the bearing capacity of PSSECs is proposed. Except for the perforated shaped steel-ECC90, the theoretical results are in good agreement with the experimental results, which should be studied in the follow-up study with special attention.

\section{Acknowledgments}

This research was supported by the National Natural Science Foundation of China (Grant No. 51608433), the Shaanxi Province Youth Science and Technology New Star Program (Grant No. 2019KJXX-040), the Shanghai Rising-Star Program (Grant No. 17QB1402300), and the State Key Laboratory of Subtropical Building Science (South China University of Technology, Grant No. 2020ZB21). These financial supports are greatly acknowledged.

\section{References}

[1] Deng M.K., Zhang Y.X. and Li Q.Q., "Shear strengthening of RC short columns with ECC jacket: Cyclic behavior tests", Engineering Structures, 160, 535-545, 2018.

[2] Said S.H. and Razak H.A., "Structural behavior of RC engineered cementitious composite (ECC) exterior beam-column joints under reversed cyclic loading", Construction and Building Materials, 107, 226-234, 2016.

[3] Fischer G. and Li V.C., "Effect of matrix ductility on deformation behavior of stee reinforced ECC flexural members under reversed cyclic loading conditions", ACI Structural Journal, 99(6), 781-790, 2002.

[4] Wu C., Pan Z.F., Su R.K.L., Leung C.K.Y. and Meng S.P., "Seismic behavior of steel reinforced ECC columns under constant axial loading and reversed cyclic lateral loading", Materials and Structures, 50, 78, 2017.

[5] Zhang Y.X., Deng M.K. and Dong Z.F., "Seismic response and shear mechanism of engineered cementitious composite (ECC) short columns", Engineering Structures, 192, 296-304, 2019.

[6] Tian L.M., Wei J.P., Hao J.P. and Wang X.T., "Method for evaluating the progressive collapse resistance of long-span single-layer spatial grid structures", Advanced Steel Construction, 15(1), 109-115, 2019.

[7] Zhou J.J., Pan J.L. and Leung C.K.Y., "Mechanical behavior of fiber-reinforced engineered cementitious composites in uniaxial compression", Journal of Materials in Civil Engineering, 27(1), 04014111, 2015

[8] Xu S.L. and Cai X.R., "Experimental study and theoretical models on compressive properties of ultrahigh toughness cementitious composites", Journal of Materials in Civil Engineering, 22(10), 1067-1077, 2010.

[9] Ding Y., Yu J.T., Yu K.Q. and Xu S.L., "Basic mechanical properties of ultra-high ductility cementitious composites: from $40 \mathrm{MPa}$ to $120 \mathrm{MPa}$ ", Composite Structures, 185, 634-645, 2018.

[10] Fu Z.Q., Ge H.B., Ji B.H. and Chen J.J., "Interface bond behavior between circular steel tube and lightweight aggregate concrete", Advanced Steel Construction, 14(3), 424-437, 2018.

[11] Zou Y., Zhou X.H., Di J. and Qin F.J., "Partial interaction shear flow forces in simply supported composite steel-concrete beams", Advanced Steel Construction, 14(4), 634-650, 2018.

[12] Zhou X.H., Gan D., Liu J. P. and Chen Y.F., "Composite effect of stub square steel tubed columns under axial compression”, Advanced Steel Construction, 14(2), 274-290, 2018.

[13] Ertas O., Ozden S. and Ozturan T., "Ductile connections in precast concrete moment resisting frames", PCI Journal, 51(3), 66-76, 2006.

[14] Ding Y., Dai X.M. and Yan J.B., "Developments and behaviors of slip-released novel connectors in steel-concrete composite structures", Advanced Steel Construction, 15(1), 30-36, 2019.

[15] Liu R.Y., Yang Y. and Zhou X.W., "Experimental study on fatigue performance of composite beam with steel-plate-concrete composite decks", Construction and Building Materials, 188, 833-849, 2018

[16] Zhang Q.H., Jia D.L., Bao Y., Cheng Z.Y., Xiao L. and Bu Y.Z., "Internal force transfer effect-based fatigue damage evaluation for PBL shear connector groups", Journal of Constructional Steel Research, 148, 469-478, 2018.

[17] Tian L.M., Hao J.P., Wei J.P. and Zheng J., "Integral lifting simulation of long-span spatial steel structures during construction", Automation in Construction, 70, 156-166, 2016.

[18] He S.H., Fang Z., Fang Y.W., Liu M., Liu L.Y. and Mosallam A.S., "Experimental study on perfobond strip connector in steel-concrete joints of hybrid bridges", Journal of Constructional Steel Research, 118, 169-179, 2016 
[19] Cândido-Martins J.P.S., Costa-Neves L.F. and Vellasco P.C.G.D.S., "Experimental evaluation of the structural response of perfobond shear connectors", Engineering Structures, 32, 1976-1985, 2010.

[20] Hosseinpour E., Baharom S., Badaruzzaman W.H.W. and Al Zand A.W., "Push-out test on the web opening shear connector for a slim-floor steel beam: Experimental and analytical study", Engineering Structures, 163, 137-152, 2018.

[21] Zhao C.H., Li Z.X., Deng K.L. and Wang W.A., "Experimental investigation on the bearing mechanism of perfobond rib shear connectors", Engineering Structures, 159, 172-184, 2018.

[22] Su Q.T., Wang W., Luan H.W. and Yang G.T., "Experimental research on bearing mechanism of perfobond rib shear connectors", Journal of Constructional Steel Research, 95, 22-31, 2014.

[23] Costa-Neves L.F., Figueiredo J.P., Vellasco P.C.G.D.S. and Vianna J.D.C., "Perforated shear connectors on composite girders under monotonic loading: An experimental approach", Engineering Structures, 56, 721-737, 2013

[24] Gu J.C., Liu D., Deng W.Q. and Zhang J.D., "Experimental study on the shear resistance of a comb-type perfobond rib shear connector", Journal of Constructional Steel Research, 158,
279-289, 2019

[25] Zuo Y.Z., Mosallam A., Xin H.H., Liu Y.Q. and He J., "Flexural performance of a hybrid GFRP-concrete bridge deck with composite T-shaped perforated rib connectors", Composite Structures, 194, 263-278, 2018

[26] Zhang J., Hu X.M., Kou L.Y., Zhang B., Jiang Y.C. and Yu H.H., "Experimental study of the short-term and long-term behavior of perfobond connectors", Journal of Constructional Steel Research, 150, 462-474, 2018.

[27] Di J., Zou Y., Zhou X.H., Qin F.J. and Peng X., "Push-out test of large perfobond connector in steel-concrete joints of hybrid bridges", Journal of Constructional Steel Research, 150, 415-429, 2018

[28] Tian L.M., Wei J.P. and Hao J.P., "Optimisation of long-span single-layer spatial grid structures to resist progressive collapse", Engineering Structures, 188, 394-405, 2019.

[29] Su Q.T., Xu Y.C., Wang W., "Theory model of shear transferring for perfobond rib connector", Journal of Tongji University (Natural Science), 41(12), 1775-1780, 2013.

[30] Guo Z.H. and Shi X.D., Reinforced concrete theory and analyse, Tsinghua University, Beijing, 2003. 